\title{
Non-genomic mechanisms of progesterone action in the brain
}

\section{Meharvan Singh*, Chang Su and Selena $\mathrm{Ng}$}

Department of Pharmacology and Neuroscience, Center FOR HER, Institute for Aging and Alzheimer's Disease Research, University of North Texas Health Science Center at Fort Worth, Fort Worth, TX, USA

\section{Edited by:}

John J. Peluso, University of

Connecticut Health Center, USA

\section{Reviewed by:}

Ikuo Kimura, Kyoto University

Graduate School of Pharmaceutical

Sciences, Japan

Paul S. Cooke, University of Florida, USA

\section{${ }^{*}$ Correspondence:}

Meharvan Singh, Department of

Pharmacology and Neuroscience,

University of North Texas Health

Science Center at Fort Worth, 3500

Camp Bowie Blvd., Fort Worth, TX

76107, USA

e-mail:meharvan.singh@unthsc.edu
Progesterone is a gonadal steroid hormone whose physiological effects extend well beyond the strict confines of reproductive function. In fact, progesterone can have important effects on a variety of tissues, including the bone, the heart and the brain. Mechanistically, progesterone has been thought to exert its effects through the progesterone receptor (PR), a member of the nuclear steroid hormone superfamily, and as such, acts through specific progesterone response elements (PRE) within the promoter region of target genes to regulate transcription of such genes. This has been often described as the "genomic" mechanism of progesterone action. However, just as progesterone has a diverse range of tissue targets, the mechanisms through which progesterone elicits its effects are equally diverse. For example, progesterone can activate alternative receptors, such as membrane-associated PRs (distinct from the classical PR), to elicit the activation of several signaling pathways that in turn, can influence cell function. Here, we review various non-nuclear (i.e., non-genomic) signaling mechanisms that progesterone can recruit to elicit its effects, focusing our discussion primarily on those signaling mechanisms by which progesterone influences cell viability in the brain.

Keywords: progesterone, non-genomic, progesterone receptor, signaling, brain

\section{THE BIOLOGY OF PROGESTERONE}

Progesterone (Pregn-4-ene-3, 20-dione, P4), the natural progestin, is a major gonadal hormone that is synthesized primarily by the ovary in the female, and the testes and adrenal cortex in the male. While progesterone levels are generally higher in the female, it is worth noting that levels of progesterone during the female follicular phase of the menstrual cycle are similar to those seen in males (Strauss and Barbieri, 2004), and thus, may have important functions in males. Although the paradigmatic role for progesterone is on reproduction function, it has also been shown to exert significant extra-reproductive actions via multiple nongenomic signaling pathways. These different functions include immunomodulation (Hughes et al., 2013), inhibition of cholesterol biosynthesis (Metherall et al., 1996), and neuroprotection (Jodhka et al., 2009).

The "classical" mechanism by which progesterone elicits its effects is via the progesterone receptor (PR), which, like the estrogen receptor (ER), has classically been described as a nuclear transcription factor, acting through specific progesterone response elements (PRE) within the promoter region of target genes to regulate transcription. Two major isoforms of the classical PR exist, $\mathrm{PR}-\mathrm{B}$, and its N-terminally truncated form, PR-A [for review, see (Conneely and Lydon, 2000)]. The latter has been shown to exert negative control of not only PR-B-mediated transcription, but that mediated by the ER and glucocorticoid receptor as well (Vegeto et al., 1993). This negative regulation of ER function by a PR may underlie, at least in part, the mechanism by which progestins functionally antagonize the effects of estrogen. For example, progesterone can inhibit estrogen's ability to increase serum levels of 1, 25, dihydroxy vitamin D (Bikle et al., 1992), whose consequence may be to antagonize estrogen's beneficial effects on the bone. Relevant to post-menopausal hormone therapy, the functional antagonism exerted by progestins on estrogen's actions also underlie the rationale for combined estrogen and progestin therapy in women with an intact uterus, as the addition of a progestin reduces the risk of uterine cancer associated with un-opposed estrogen therapy (Hirvonen, 1996). However, the relationship between progesterone and ERs may not always be antagonistic. For example, Migliaccio et al. demonstrated not only a physical interaction of the PR with the ER, but that this association was necessary for progesterone to elicit the activation of a signal transduction pathway, the mitogen activated protein kinase (MAPK) pathway, in mammary tumor cells (Migliaccio et al., 1998).

While the classical mechanism by which progesterone elicits its actions is through the regulation of gene expression, progesterone has also been shown to elicit its effects via non-genomic mechanisms such as through the activation of signal transduction pathways, which in turn may be mediated by distinct PRs, including the more recently described membrane-associated PRs. Here, we review various non-nuclear signaling mechanisms by which progesterone can elicit its effects, focusing our discussion primarily on non-nuclear mechanisms by which progesterone influences cell viability in the brain. 


\section{DIVERSITY OF SIGNALING PATHWAYS THAT MEDIATE THE EFFECTS OF PROGESTERONE}

The classical PR-mediated cellular/physiological effects of progesterone are generally not rapidly elicited, given the time required to induce the transcription of genes and then, translate those genes into protein products. In contrast, it is now clear that progesterone can elicit rapid, non-genomic actions in various tissues including the brain through alternative mechanisms. These "non-classical" effects of progesterone can be initiated rapidly at the cell surface to activate intracellular signaling pathways, through modulation of putative cell surface receptors, ion channels, and cytoplasmic second messenger cascades. It is worth noting, however, that though these effects of progesterone are termed "non-genomic," the rapid activation of cytoplasmic kinase signaling can result in both transcription-independent and transcription-dependent effects.

Among those rapid non-nuclear signaling pathways known to be activated by progesterone include the extracellular signalrelated kinase (ERK) pathways (Migliaccio et al., 1998; Singh, 2001; Nilsen and Brinton, 2002; Boonyaratanakornkit et al., 2008; Su et al., 2012), cAMP/protein kinase A (PKA) signaling (Collado et al., 1985; Petralia and Frye, 2006), PKG signaling (Peluso, 2003), $\mathrm{Ca}^{2+}$ influx/PKC activation (Swiatek-De Lange et al., 2007), phosphatidylinositol 3-kinases (PI3 K)/Akt pathway (Singh, 2001; Zheng et al., 2012) and other signal transduction cascades. In addition, progesterone (or its metabolites) can act directly and rapidly on such neurotransmitter receptors such as the GABA-A receptor (Ishihara et al., 2013) and Sigma-1/2 receptors (Cai et al., 2008; Xu et al., 2011) to regulate cellular function.

With respect to calcium signaling, several reports suggest a functional link between progesterone and intracellular $\mathrm{Ca}^{2+}$ levels $\left[\left(\mathrm{Ca}^{2+}\right)_{i}\right]$. For example, progesterone elicits increases in intracellular $\mathrm{Ca}^{2+}\left[\left(\mathrm{Ca}^{2+}\right)_{i}\right]$ levels in Xenopus oocytes resulting in oocyte maturation (Wasserman et al., 1980). However, the cellular mediators involved in the progesterone-mediated changes in $\left[\mathrm{Ca}^{2+}\right]_{i}$ remain to be determined. What is known is that intracellular $\mathrm{Ca}^{2+}$ channels (ICCs), such as IP3Rs, have been shown to be major components of the cytosolic $\mathrm{Ca}^{2+}$ regulation machinery (Berridge et al., 2000, 2003). Furthermore, several steroid hormones activate other signaling molecules that might in turn lead to activation of ICCs. In fact, both estradiol and progesterone elicit the phosphorylation of Akt in cerebral cortical cultures (Singh, 2001), a signaling protein that has been implicated in the phosphorylation of $\mathrm{IP}_{3}$ Rs in Chinese hamster ovary T-cells (Khan et al., 2006). Progesterone, through an Akt-dependent pathway, can activate $\mathrm{IP}_{3} \mathrm{R}$ type 2 , leading to enhancing channel activity of $\mathrm{IP}_{3} \mathrm{R}$ type 2 (Koulen et al., 2008; Hwang et al., 2009).

The consequences of activation of these signaling pathways are numerous and include influences on neurotrophin release (Su et al., 2012), neural progenitor proliferation (Liu et al., 2009), regulation of intracellular $\mathrm{Ca}^{2+}$ levels (Cai et al., 2008), and regulation of cell viability (Nilsen and Brinton, 2002, 2003; Kaur et al., 2007; Ishihara et al., 2013), all of which can contribute to the overall health and function of the brain.

\section{RECEPTORS MEDIATORS OF PROGESTERONE-INDUCED SIGNALING}

From a receptor pharmacology standpoint, the mechanism of progesterone action implicates the classical PR (e.g., PR-B or its $\mathrm{N}$-terminally truncated variant, PR-A). Indeed, there are neuroprotective mechanisms of progesterone that require the classical PR. For example, our laboratory has determined that the ability of progesterone to increase the expression (mRNA and protein levels) of brain-derived neurotrophic factor (BDNF), a key mediator of progesterone's protective effects, requires the classical PR (Figure 1) (Jodhka et al., 2009). Further, Cai and colleagues (2008) have implicated the classical/intracellular PR in the protective effects of progesterone against an experimental model (middle cerebral artery occlusion) of stroke. However, evidence also exists for alternative mechanisms of action, including that which involves integral membrane PRs. For example, the effect of progesterone has been reported in the brain of PR knock-out mice (Krebs et al., 2000), suggesting PRs other than the classical PR may mediate the effect of progesterone in the CNS. In fact, several lines of evidence now support the role of cell membraneassociated PRs in mediating the effects of progesterone on the

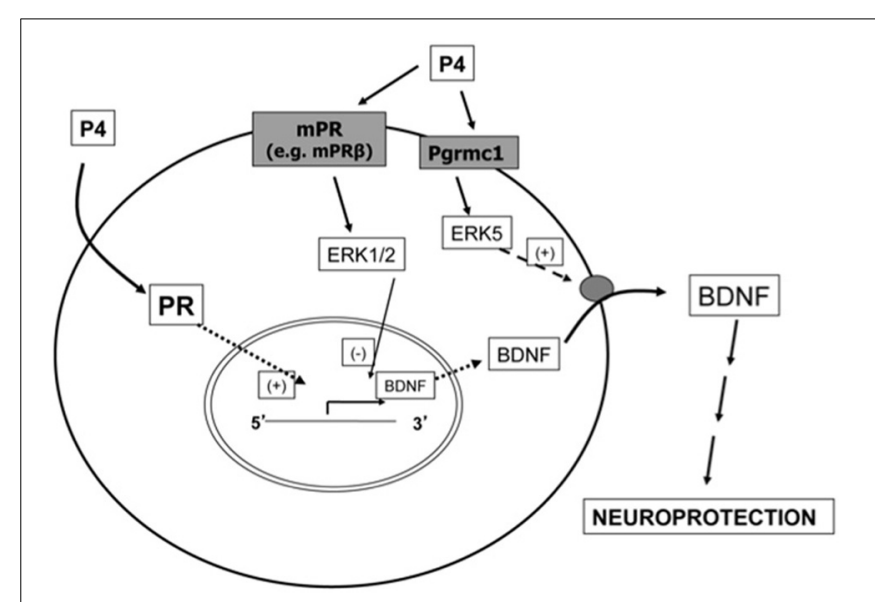

FIGURE 1 | Mechanism of progesterone action in the brain. This figure provides a conceptual overview of how progesterone can elicit both genomic and non-genomic effects that impact its protective effects on the brain, and exemplifies how activation of complementary signaling cascades may be required for progesterone to fully elicit its effects. Using BDNF and two members of the ERK/MAPK family as paradigmatic examples of key mediators of progesterone-induced neuroprotection, this diagram underscores the fact that the protective effects of progesterone cannot be elicited by one signaling pathway alone, but rather, require complementary activation of multiple signaling pathways. In this example, the induction of BDNF synthesis requires the PR operating through its classical, genomic mechanism of action. However, such synthesis may not be meaningful unless the cellular content of BDNF can be secreted, leading in turn to the activation of its cognate receptors (ex. TrkB and/or p75) which can then elicit additional signaling pathways associated with cellular protection. This release of BDNF is mediated by a distinct receptor, Pgrmc1. In addition, other membrane-associated progesterone receptors, such as the MPR family of receptors, may elicit the activation of related signaling pathways that help finely regulate the process. In the example illustrated, activation of mPR may lead to activation of ERK1/2, which in turn, has been shown to exert an inhibitory influence on BDNF gene expression. 
brain (Balasubramanian et al., 2008; Liu and Arbogast, 2009; Tokmakov and Fukami, 2009; Intlekofer and Petersen, 2011). The notion that membrane PRs exist is not new, and in fact, was supported by Hans Selye's pioneer work in the 40's that showed various steroid hormones, including progesterone, had very rapid anesthetic effects in contrast to the delayed "main" hormone actions (Selye, 1942). Four decades later, specific, displaceable binding sites for progesterone were identified in synaptosomal membrane preparations (Towle and Sze, 1983; Ke and Ramirez, 1990). Further, progesterone's is quite lipophilic, having a $\log P$ value, or octanol/water partition coefficient, of 4 . This value reflects the relative solubility of a compound in an organic phase (i.e., octanol) vs. an aqueous phase (e.g., water). As such, a $\log P$ value of 4 indicates that for every molecule of progesterone that partitions into the aqueous phase, 10,000 molecules partition into the organic phase. This further supports the idea that progesterone interacts with a plasma membrane-associated receptor.

Two types of distinct cell surface-associated proteins unrelated to classical PRs have been identified so far: membrane PRs (mPRs) and the progesterone membrane receptor component (PGMRC). The mPRs (molecular mass of approximately $40 \mathrm{kDa}$ ) had thought to be comprised of three subtypes, $\operatorname{mPR} \alpha, \beta$, and $\gamma$, which belong to the seven-transmembrane domain adiponectin $\mathrm{Q}$ receptor (PAQR) family (Zhu et al., 2003a,b). Two new subtypes, $\mathrm{mPR} \delta$ and $\mathrm{mPR} \varepsilon$, have also been characterized recently in human brain (Pang et al., 2013). The mPRs bind to progesterone with high affinity $\left(K_{d} \sim 5 \mathrm{nM}\right)$ (Zhu et al., 2003a), and mediate important physiological functions in male and female reproductive tracts, liver, neuroendocrine tissues, and the immune system as well as in breast and ovarian cancer (Sleiter et al., 2009; Pang and Thomas, 2011). Uniquely, recent experimental evidence supports mPRs as G-protein-coupled receptors, as supported by the observation that activation of the $\mathrm{mPR} \alpha$ can result in recruitment/activation of pertussis-sensitive inhibitory proteins $\left(G_{i}\right)$ to down-regulate membrane-bound adenylyl cyclase activity in the sea trout and in humans (Thomas et al., 2007).

Despite the fact that the classical PR and mPRs have overlapping regional expression (e.g., both are expressed in the hippocampus, cortex, hypothalamus, and cerebellum) (Brinton et al., 2008; Meffre et al., 2013), their profile of ligand specificity is not identical. For example, mPRs bind to $17 \alpha$ hydroxyprogesterone and 5-dihydroprogesterone with greater affinity than to the classical PRs (Grazzini et al., 1998; Smith et al., 2008). In terms of cellular distribution, under non-injured conditions, the mPR $\alpha$ isoform was expressed principally by neuronal cells and not by oligodendrocytes or astrocytes. However, following traumatic brain injury (TBI) $\mathrm{mPR} \alpha$ expression was observed in oligodendrocytes, astrocytes, and reactive microglia. This increase in $\mathrm{mPR}$ expression was proposed to mediate the anti-inflammatory effects of progesterone under conditions of injury (Meffre et al., 2013). Thus, the complement of PRs expressed in the brain may be driven by the health of the tissue.

In comparison to the mPRs, the single-transmembrane protein Pgrmcl (molecular mass $25-28 \mathrm{kDa}$ ) and the closely related Pgrmc2 are thought to be a part of a multi-protein complex that binds to progesterone and other steroids, as well as pharmaceutical compounds (Thomas, 2008). Pgrmc1 was originally discovered in porcine liver and vascular smooth muscles (Falkenstein et al., 1996; Meyer et al., 1998), and later cloned in other species, including humans. Pgrmcl has also been termed 25-Dx in rat and Hpr6 in human [for review, see (Cahill, 2007)], a result of being identified in different biological systems from multiple species. Pgrmcl has an N-terminal transmembrane domain and a putative cytoplasmic cytochrome $b 5$ domain ligand-binding motif. The cytoplasmic domain has target sequences for binding by SH2- and SH3-domain containing proteins as well as tyrosine kinases, implicating a potential role for Pgrmcl as an adaptor involved in protein interactions and intracellular signal transduction. The subcellular localization of Pgrmc1 has been open to argument, since it was reported to localize in endoplasmic reticulum (Nolte et al., 2000), Golgi apparatus (Sakamoto et al., 2004) and nuclei (Beausoleil et al., 2004). However, evidence supporting the cell surface localization of Pgrmcl includes the reports by Peluso et al., (Peluso et al., 2005) and ours (Su et al., 2012), in which biotinylated Pgrmc1 was localized to the surface (i.e., plasma membrane) of non-permeabilized cells.

Both mPRs and Pgrmc are expressed at high levels in the brain, but their functions relevant to progesterone effect in the CNS have only just started to be revealed. For example, a recent report demonstrated that allopregnanolone and other neurosteroids bound to $\mathrm{mPR} \delta$ and decreased starvation-induced apoptosis in in hippocampal neuronal cells at low nanomolar concentrations (Pang et al., 2013). In addition, $\mathrm{mPR} \alpha, \mathrm{mPR} \beta$ and Pgrmcl have been implicated in progesterone-repressed gonadotrophinreleasing hormone release from hypothalamic neurons (Sleiter et al., 2009; Bashour and Wray, 2012). Progesterone-increased neural progenitor proliferation may also be mediated by Pgrmc1 as this effect was blocked by siRNA against Pgrmc1/2 (Liu et al., 2009). Further, a recent study by Frye, et al., revealed that progesterone-facilitated lordosis (sexual behavior) was significantly reduced by antisense oligodeoxynucleotides (AS-ODNs) against $\mathrm{mPR} \beta$, or AS-ODNs against both $\operatorname{mPR} \beta$ and $\mathrm{mPR} \alpha$, when administered into the ventral tegmental area (VTA) (Frye et al., 2013). This data supports the potential role of mPRs in progesterone-facilitated lordosis of rats. The cell signaling pathways and associated downstream effects for progesterone-induced non-genomic actions are summarized in Table 1.

The functions of membrane-associated PRs in the CNS are not limited to neurons. In fact, work from our laboratory supports that progesterone triggers BDNF release via Pgrmcl signaling specifically from glia (Su et al., 2012). Another report showed that $\mathrm{mPR} \alpha$ expression was induced in oligodendrocytes, astrocytes and reactive microglia after TBI (Meffre et al., 2013), supporting a potential role in mediating the effects of progesterone in inflammation and water homeostasis in the injured brain.

The two receptors do not always work independently. For example, Thomas and colleagues reported that activation of $\mathrm{mPR} \alpha$ and $-\beta$ in human myometrium leads to transactivation of PR-B (Karteris et al., 2006), as the first evidence that cross talk between the classical PR signaling and membrane-associated PR signaling exists. 
Table 1 | Receptor pharmacology and signaling pathways associated with progesterone-induced non-genomic effects.

\begin{tabular}{llll}
\hline Receptor & Signaling pathway & Effect & Species/cell/tissue type [references] \\
\hline PR & $G_{\beta \gamma} /$ adenylyl cyclase & Oocyte maturation & Xenopus oocyte [Guzman et al., 2005; Evaul et al., 2007] \\
PR & Src/ERK1/2/PI3K/Akt & Activation of transcription factors (e.g., Elk1) & Breast cancer [Saitoh et al., 2005; Fu et al., 2008] \\
PR & Src/RhoA & Inhibition of proliferation & Smooth muscle cells [Hsu et al., 2011] \\
Pgrmc1 & ERK5 & BDNF release & Glia [Su et al., 2012] \\
Pgrmc1, mPR $\alpha, m P R \beta$ & N.D. & GnRH release & Hypothalamic neurons [Sleiter et al., 2009] \\
Pgrmc1/2 & ERK & Neuronal progenitor proliferation & Dentate gyrus [Liu et al., 2009] \\
$m P R \alpha, m P R \beta$ & N.D. & Lordosis & Ventral tegmental area [Frye et al., 2013] \\
$m P R \alpha$ & G $/$ adenylyl cyclase & N.D. & Sea trout, humans [Thomas et al., 2007] \\
$m P R \beta$ & MAPK & Oocyte maturation & Xenopus oocyte [Josefsberg Ben-Yehoshua et al., 2007] \\
N.D. & $\uparrow\left[C a^{2+}\right]_{i}$ & Oocyte maturation & Xenopus oocyte [Wasserman et al., 1980] \\
\hline
\end{tabular}

BDNF, brain-derived neurotrophic factor; ERK, extracellular-signal regulated kinase; GnRH, gonadotropin releasing hormone; $M A P K$, mitogen-activated protein kinase;

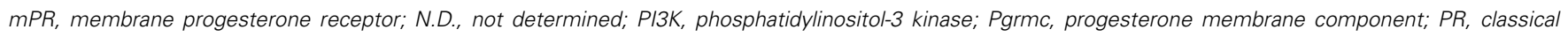
progesterone receptor.

It is also worth noting that the classical PR can also mediate the effects of progesterone on signaling pathways through non-genomic/extranuclear mechanisms of progesterone. Human PR-B contains a polyproline motif in its aminoterminal domain that interacts with the $\mathrm{SH} 3$ domain of $\mathrm{Src}$ (Boonyaratanakornkit et al., 2001). Therefore, cytoplasmic PR can mediate progesterone-induced rapid activation of c-Src and downstream Ras/Raf/ERK1/2 signaling independent of its transcriptional activity. Activation of the MAPK pathway ultimately results in the phosphorylation/activation of transcription factors such as c-Fos, c-Jun and nuclear PRs to control gene transcription. For example, progesterone was shown to inhibit aortic smooth muscle cell proliferation via Src phosphorylation that in turn, results in RhoA inactivation. The involvement of the PR was supported by the fact that this effect was blocked by RU486, a PR antagonist (Hsu et al., 2011). PR also mediates progesterone's effects on breast cancer development and progression by activating the Src/ERK1/2 or PI3K/Akt pathways (Saitoh et al., 2005; Fu et al., 2008), which leads to activation of the transcription factor Elk-1 and consequent changes in gene expression (Boonyaratanakornkit et al., 2008).

In addition to the well-characterized Src pathway downstream of extranuclear PR, there is evidence supporting the activation of G-protein signaling by PR in frogs (Xenopus laevis). For example, the Xenopus PR isoform related to the mammalian PR-B localizes to the plasma membrane of oocytes, and that activation of the PR regulates Xenopus oocyte maturation via the $\mathrm{G} \beta \gamma$ activation of adenylyl cyclase (Guzman et al., 2005; Evaul et al., 2007). Interestingly, another study concluded that the Xenopus ortholog of mPR $\beta$ mediated progesterone-induced oocyte maturation via the MAPK signaling (Josefsberg Ben-Yehoshua et al., 2007). Whether there is a cross talk between the PR/G $\beta \gamma$ pathway and the mPR $\beta / M A P K$ pathway in this system remains unclear.

\section{REGULATION OF BRAIN FUNCTION THROUGH METABOLITES OF PROGESTERONE}

Another mechanism by which progesterone can exert protective effects is through its metabolites, which in turn, can interact with membrane-associated receptors coupled to ion-channels, such as the $\mathrm{GABA}_{\mathrm{A}}$ receptor system [see (Deutsch et al., 1992) for review]. Such metabolites include allopregnanolone (or $3 \alpha$, $5 \alpha$ tetrahydroprogesterone), which bind to discrete sites within the hydrophobic domain of the $\mathrm{GABA}_{\mathrm{A}}$ receptor complex, and result in the potentiation of GABA-induced chloride conductance. Indeed, allopregnanolone has been suggested to play a role in mediating the protective effects of progesterone (Djebaili et al., 2004; He et al., 2004a,b; Vitarbo et al., 2004; Ardeshiri et al., 2006; Sayeed et al., 2009). In addition to the effects of allopregnanolone on the $\mathrm{GABA}_{\mathrm{A}}$ receptor, as outlined above, allopregnanolone may also elicit its protective effects through its actions on the mitochondria (Robertson et al., 2006). For example, allopregnanolone was reported to inhibit currents associated with the opening of the mitochondrial permeability transition pore (mtPTP) (Sayeed et al., 2009), and as such, may help reduce the potential apoptotic consequences of mtPTP opening (such as cytochrome c release) during insult or injury. Moreover, allopregnanolone has also been shown to exert significant effects on neurogenesis [see (Wang et al., 2008) and references cited therein for review]. Interestingly, it has been shown that allopregnanolone may also elicit its protective effects through the regulation of BDNF [see (Nin et al., 2011) and references cited therein], although the precise mechanism by which allopregnanolone elicits BDNF [i.e., what receptor(s) allopregnanolone works through] is still unclear.

In addition to the allosteric effects described above, progesterone itself may have non-allosteric influences on the $\mathrm{GABA}_{\mathrm{A}}$ receptor. Progesterone may influence the $\mathrm{GABA}_{\mathrm{A}}$ receptor via the activation of a signal transduction pathway, which in turn, influences GABA-gated currents through phosphorylation of discrete sites within certain subunits of the $G_{A B A}$ receptor (Vasan et al., 2003; Bell-Horner et al., 2006). Since the regulation of the $\mathrm{GABA}_{\mathrm{A}}$ receptor has been shown to modulate cell survival, particularly in models of excitotoxicity, the regulation of the $\mathrm{GABA}_{\mathrm{A}}$ receptor by progesterone may be relevant to the protective effect of progesterone seen against kainateinduced seizure activity and subsequent cell death (Hoffman et al., 2003). 
And yet another non-classical by which progesterone can elicit its effects is through its interaction with the sigma $1\left(\sigma_{1}\right)$ receptor (Selmin et al., 1996; Seth et al., 1998). Given the reported role of the sigma 1 receptor in neuroprotection [for review, see (Maurice et al., 2006)], this mechanism may also be relevant to progesterone's protective actions.

Collectively, reports from numerous laboratories support the critical involvement of "non-genomic" signaling in mediating progesterone's effects, including its cytoprotective effects. This highlights not only the complexity by which progesterone exerts its effects on target tissues, but

\section{REFERENCES}

Ardeshiri, A., Kelley, M. H., Korner, I. P., Hurn, P. D., and Herson, P. S. (2006). Mechanism of progesterone neuroprotection of rat cerebellar Purkinje cells following oxygenglucose deprivation. Eur. J. Neurosci. 24, 2567-2574. doi: 10.1111/j.14609568.2006.05142.x

Balasubramanian, B., Portillo, W., Reyna, A., Chen, J. Z., Moore, A. N., Dash, P. K., et al. (2008). Nonclassical mechanisms of progesterone action in the brain: II. Role of calmodulindependent protein kinase II in progesterone-mediated signaling in the hypothalamus of female rats. Endocrinology 149, 5518-5526. doi: 10.1210/en.2008-0713

Bashour, N. M., and Wray, S. (2012). Progesterone directly and rapidly inhibits GnRH neuronal activity via progesterone receptor membrane component 1. Endocrinology 153, 4457-4469. doi: 10.1210/en.20121122

Beausoleil, S. A., Jedrychowski, M., Schwartz, D., Elias, J. E., Villen, J., Li, J., et al. (2004). Large-scale characterization of HeLa cell nuclear phosphoproteins. Proc. Natl. Acad. Sci. U.S.A. 101, 12130-12135. doi: 10.1073/pnas.0404720101

Bell-Horner, C. L., Dohi, A., Nguyen, Q., Dillon, G. H., and Singh, M. (2006). ERK/MAPK pathway regulates GABAA receptors. J. Neurobiol. 66, 1467-1474. doi: 10.1002/neu.20327

Berridge, M. J., Bootman, M. D., and Roderick, H. L. (2003). Calcium signalling: dynamics, homeostasis and remodelling. Nat. Rev. Mol. Cell Biol. 4, 517-529. doi: 10.1038/nrm1155

Berridge, M. J., Lipp, P., and Bootman, M. D. (2000). The versatility and universality of calcium signalling. Nat. Rev. Mol. Cell Biol. 1, 11-21. doi: 10.1038/35036035

Bikle, D. D., Halloran, B. P., Harris, S. T., and Portale, A. A.
(1992). Progestin antagonism of estrogen stimulated 1,25dihydroxyvitamin D levels. J. Clin. Endocrinol. Metab. 75, 519-523. doi: 10.1210/jc.75.2.519

Boonyaratanakornkit, V., Bi, Y., Rudd, M., and Edwards, D. P. (2008). The role and mechanism of progesterone receptor activation of extra-nuclear signaling pathways in regulating gene transcription and cell cycle progression. Steroids 73, 922-928. doi: 10.1016/j.steroids.2008.01.010

Boonyaratanakornkit, V., Scott, M. P., Ribon, V., Sherman, L., Anderson, S. M., Maller, J. L., et al. (2001). Progesterone receptor contains a proline-rich motif that directly interacts with $\mathrm{SH} 3$ domains and activates c-Src family tyrosine kinases. Mol. Cell 8, 269-280. doi: 10.1016/S1097-2765(01)00304-5

Brinton, R. D., Thompson, R. F., Foy, M. R., Baudry, M., Wang, J., Finch, C. E., et al. (2008). Progesterone receptors: form and function in brain. Front. Neuroendocrinol. 29, 313-339. doi: 10.1016/j.yfrne.2008.02.001

Cahill, M. A. (2007). Progesterone receptor membrane component 1 : an integrative review. J. Steroid Biochem. Mol. Biol. 105, 16-36. doi: 10.1016/j.jsbmb.2007.02.002

Cai, W., Zhu, Y., Furuya, K., Li, Z., Sokabe, M., and Chen, L. (2008). Two different molecular mechanisms underlying progesterone neuroprotection against ischemic brain damage. Neuropharmacology 55, 127-138. doi: 10.1016/j. neuropharm.2008.04.023

Collado, M. L., Rodriguez-Manzo, G., and Cruz, M. L. (1985). Effect of progesterone upon adenylate cyclase activity and cAMP levels on brain areas. Pharmacol. Biochem. Behav. 23, 501-504. doi: 10.1016/00913057(85)90408-3

Conneely, O. M., and Lydon, J. P. (2000). Progesterone receptors in reproduction: functional impact of the $\mathrm{A}$ and $\mathrm{B}$ isoforms. Steroids

also reveals insight into discrete mechanisms that may be modulated for the purpose of developing novel therapeutic strategies.

\section{ACKNOWLEDGMENTS}

This work was supported in part by funds from the National Institutes of Health (AG022550 and AG027956), an InvestigatorInitiated Research Grant from the Alzheimer's Association, and the Texas Garvey Foundation to Meharvan Singh, and funds from the American Federation of Aging Research, and American Heart Association to Chang Su.

65, 571-577. doi: 10.1016/S0039128X(00)00115-X

Deutsch, S. I., Mastropaolo, J., and Hitri, A. (1992). GABA-active steroids: endogenous modulators of GABA-gated chloride ion conductance. Clin. Neuropharmacol. 15, 352-364. doi: 10.1097/00002826199210000-00002

Djebaili, M., Hoffman, S. W., and Stein, D. G. (2004). Allopregnanolone and progesterone decrease cell death and cognitive deficits after a contusion of the rat pre-frontal cortex. Neuroscience 123, 349-359. doi: 10.1016/j.neuroscience.2003.09.023

Evaul, K., Jamnongjit, M., Bhagavath, B., and Hammes, S. R. (2007). Testosterone and progesterone rapidly attenuate plasma membrane Gbetagamma-mediated signaling in Xenopus laevis oocytes by signaling through classical steroid receptors. Mol. Endocrinol. 21, 186-196. doi: 10.1210/me.2006-0301

Falkenstein, E., Meyer, C., Eisen, C. Scriba, P. C., and Wehling, M. (1996). Full-length cDNA sequence of a progesterone membranebinding protein from porcine vascular smooth muscle cells. Biochem. Biophys. Res. Commun. 229, 86-89. doi: 10.1006/bbrc. 1996. 1761

Frye, C. A., Walf, A. A., Kohtz, A. S., and Zhu, Y. (2013). Membrane progestin receptors in the midbrain ventral tegmental are required for progesterone-facilitated lordosis of rats. Horm. Behav. doi: 10.1016/j. yhbeh.2013.05.012. [Epub ahead of print].

Fu, X. D., Giretti, M. S., Baldacci, C., Garibaldi, S., Flamini, M., Sanchez, A. M., et al. (2008). Extra-nuclear signaling of progesterone receptor to breast cancer cell movement and invasion through the actin cytoskeleton. PLoS ONE 3:e2790. doi:10.1371/journal.pone. 0002790

Grazzini, E., Guillon, G., Mouillac, B., and Zingg, H. H. (1998)
Inhibition of oxytocin receptor function by direct binding of progesterone. Nature 392, 509-512. doi: $10.1038 / 33176$

Guzman, L., Romo, X., Grandy, R., Soto, X., Montecino, M., Hinrichs, M., et al. (2005). A Gbetagamma stimulated adenylyl cyclase is involved in Xenopus laevis oocyte maturation. J. Cell. Physiol. 202, 223-229. doi: 10.1002/jcp.20102

He, J., Evans, C. O., Hoffman, S. W., Oyesiku, N. M., and Stein, D. G. (2004a). Progesterone and allopregnanolone reduce inflammatory cytokines after traumatic brain injury. Exp. Neurol. 189, 404-412. doi: $\quad 10.1016 /$ j.expneurol.2004 06.008

He, J., Hoffman, S. W., and Stein, D. G. (2004b). Allopregnanolone, a progesterone metabolite, enhances behavioral recovery and decreases neuronal loss after traumatic brain injury. Restor. Neurol. Neurosci. 22, 19-31.

Hirvonen, E. (1996). Progestins. Maturitas 23(Suppl.), S13-S18. doi: 10.1016/0378-5122(96)01005-5

Hoffman, G. E., Moore, N., Fiskum, G., and Murphy, A. Z. (2003). Ovarian steroid modulation of seizure severity and hippocampal cell death after kainic acid treatment. Exp. Neurol. 182, 124-134. doi: 10.1016/S00144886(03)00104-3

Hsu, S. P., Chen, T. H., Chou, Y. P., Chen, L. C., Kuo, C. T., Lee, T. S. et al. (2011). Extra-nuclear activation of progesterone receptor in regulating arterial smooth muscle cell migration. Atherosclerosis 217, 83-89. doi: 10.1016/j. atherosclerosis.2011.02.051

Hughes, G. C., Clark, E. A., and Wong, A. H. (2013). The intracellular progesterone receptor regulates CD4+ $\mathrm{T}$ cells and $\mathrm{T}$ cell-dependent antibody responses. J. Leukoc. Biol. 93, 369-375. doi: 10.1189/jlb.1012491

Hwang, J. Y., Duncan, R. S., Madry, C., Singh, M., and Koulen, P. (2009). Progesterone potentiates calcium 
release through IP3 receptors by an Akt-mediated mechanism in hippocampal neurons. Cell Calcium 45, 233-242. doi: 10.1016/j.ceca.2008. 10.006

Intlekofer, K. A., and Petersen, S. L. (2011). Distribution of mRNAs encoding classical progestin receptor, progesterone membrane components 1 and 2, serpine mRNA binding protein 1 , and progestin and ADIPOQ receptor family members 7 and 8 in rat forebrain. Neuroscience 172, 55-65. doi: $\quad 10.1016 / j$. neuroscience.2010. 10.051

Ishihara, Y., Kawami, T., Ishida, A., and Yamazaki, T. (2013). Allopregnanolone-mediated protective effects of progesterone on tributyltin-induced neuronal injury in rat hippocampal slices. J. Steroid Biochem. Mol. Biol. 135, 1-6. doi: 10.1016/j.jsbmb.2012.12.013

Jodhka, P. K., Kaur, P., Underwood, W., Lydon, J. P., and Singh, M. (2009). The differences in neuroprotective efficacy of progesterone and medroxyprogesterone acetate correlate with their effects on brainderived neurotrophic factor expression. Endocrinology 150, 3162-3168. doi: 10.1210/en.2008-1247

Josefsberg Ben-Yehoshua, L., Lewellyn, A. L., Thomas, P., and Maller, J. L. (2007). The role of Xenopus membrane progesterone receptor beta in mediating the effect of progesterone on oocyte maturation. Mol. Endocrinol. 21, 664-673. doi: 10.1210/me.2006-0256

Karteris, E., Zervou, S., Pang, Y., Dong, J., Hillhouse, E. W., Randeva, H. S., et al. (2006). Progesterone signaling in human myometrium through two novel membrane $G$ proteincoupled receptors: potential role in functional progesterone withdrawal at term. Mol. Endocrinol. 20, 1519-1534. doi: 10.1210/me.20050243

Kaur, P., Jodhka, P. K., Underwood, W. A., Bowles, C. A., De Fiebre, N. C., De Fiebre, C. M., et al. (2007). Progesterone increases brain-derived neuroptrophic factor expression and protects against glutamate toxicity in a mitogen-activated protein kinaseand phosphoinositide-3 kinasedependent manner in cerebral cortical explants. J. Neurosci. Res. 85, 2441-2449. doi: 10.1002/jnr.21370

Ke, F. C., and Ramirez, V. D. (1990). Binding of progesterone to nerve cell membranes of rat brain using progesterone conjugated to 125I-bovine serum albumin as a ligand. J. Neurochem. 54,
467-472. doi: 10.1111/j.14714159.1990.tb01895.x

Khan, M. T., Wagner, L. 2nd., Yule, D. I., Bhanumathy, C., and Joseph, S. K. (2006). Akt kinase phosphorylation of inositol 1,4,5-trisphosphate receptors. J. Biol. Chem. 281, 3731-3737. doi: 10.1074/jbc.M509262200

Koulen, P., Madry, C., Duncan, R. S., Hwang, J. Y., Nixon, E., McClung, N., et al. (2008). Progesterone potentiates IP(3)-mediated calcium signaling through Akt/PKB. Cell. Physiol. Biochem. 21, 161-172. doi: 10.1159/000113758

Krebs, C. J., Jarvis, E. D., Chan, J., Lydon, J. P., Ogawa, S., and Pfaff, D. W. (2000). A membrane-associated progesterone-binding protein, $25-\mathrm{Dx}$, is regulated by progesterone in brain regions involved in female reproductive behaviors. Proc. Natl. Acad. Sci. U.S.A. 97, 12816-12821. doi: 10.1073/pnas.97. 23.12816

Liu, B., and Arbogast, L. A. (2009). Gene expression profiles of intracellular and membrane progesterone receptor isoforms in the mediobasal hypothalamus during pro-oestrus. J. Neuroendocrinol. 21, 993-1000. doi: 10.1111/j.13652826.2009.01920.x

Liu, L., Wang, J., Zhao, L., Nilsen, J., McClure, K., Wong, K., et al. (2009). Progesterone increases rat neural progenitor cell cycle gene expression and proliferation via extracellularly regulated kinase and progesterone receptor membrane components 1 and 2. Endocrinology 150, 3186-3196. doi: 10.1210/en.20081447

Maurice, T., Gregoire, C., and Espallergues, J. (2006). Neuro(active)steroids actions at the neuromodulatory sigmal (sigmal) receptor: biochemical and physiological evidences, consequences in neuroprotection. Pharmacol. Biochem. Behav. 84, 581-597. doi: 10.1016/j.pbb.2006.07.009

Meffre, D., Labombarda, F., Delespierre, B., Chastre, A., De Nicola, A. F., Stein, D. G., et al. (2013). Distribution of membrane progesterone receptor alpha in the male mouse and rat brain and its regulation after traumatic brain injury. Neuroscience 231, 111-124. doi: $10.1016 /$ j.neuroscience. 2012 . 11.039

Metherall, J. E., Li, H., and Waugh, K. (1996). Role of multidrug resistance P-glycoproteins in cholesterol biosynthesis. J. Biol. Chem. 271, 2634-2640. doi: 10.1074/jbc.271.5. 2634
Meyer, C., Schmid, R., Schmieding, K., Falkenstein, E., and Wehling, M. (1998). Characterization of high affinity progesterone-binding membrane proteins by anti-peptide antiserum. Steroids 63, 111-116. doi: 10.1016/S0039-128X(97)00143-8

Migliaccio, A., Piccolo, D., Castoria, G., Di Domenico, M., Bilancio, A., Lombardi, M., et al. (1998). Activation of the Src/p21ras/Erk pathway by progesterone receptor via cross-talk with estrogen receptor. EMBO J. 17, 2008-2018. doi: 10.1093/emboj/ 17.7.2008

Nilsen, J., and Brinton, R. D. (2002). Impact of progestins on estrogen-induced neuroprotection: synergy by progesterone and 19norprogesterone and antagonism by medroxyprogesterone acetate. Endocrinology 143, 205-212. doi 10.1210/en.143.1.205

Nilsen, J., and Brinton, R. D. (2003). Divergent impact of progesterone and medroxyprogesterone acetate (Provera) on nuclear mitogen-activated protein kinase signaling. Proc. Natl. Acad. Sci. U.S.A. 100, 10506-10511. doi: 10.1073/pnas. 1334098100

Nin, M. S., Martinez, L. A., Pibiri, F., Nelson, M., and Pinna, G. (2011). Neurosteroids reduce social isolation-induced behavioral deficits: a proposed link with neurosteroid-mediated upregulation of BDNF expression. Front. Endocrinol. (Lausanne) 2:73. doi: 10.3389/fendo.2011.00073

Nolte, I., Jeckel, D., Wieland, F. T., and Sohn, K. (2000). Localization and topology of ratp28, a member of a novel family of putative steroid-binding proteins. Biochim. Biophys. Acta 1543, 123-130. doi: 10.1016/S0167-4838(00)00188-6

Pang, Y., Dong, J., and Thomas, P. (2013). Characterization, neurosteroid binding and brain distribution of human membrane progesterone receptors delta and \{epsilon\} (mPRdelta and $\operatorname{mPR}\{$ epsilon\}) and mPRdelta involvement in neurosteroid inhibition of apoptosis. Endocrinology 154, 283-295. doi: 10.1210/en.2012-1772

Pang, Y., and Thomas, P. (2011). Progesterone signals through membrane progesterone receptors (mPRs) in MDA-MB-468 and mPRtransfected MDA-MB-231 breast cancer cells which lack full-length and N-terminally truncated isoforms of the nuclear progesterone receptor. Steroids 76, 921-928. doi: 10.1016/j.steroids.2011.01.008
Peluso, J. J. (2003). Progesterone as a regulator of granulosa cell viability. J. Steroid Biochem. Mol. Biol. 85, 167-173. doi: 10.1016/S09600760(03)00192-4

Peluso, J. J., Pappalardo, A., Losel, R., and Wehling, M. (2005). Expression and function of PAIRBP1 within gonadotropin-primed immature rat ovaries: PAIRBP1 regulation of granulosa and luteal cell viability. Biol. Reprod. 73, 261-270. doi: 10.1095/biolreprod.105.041061

Petralia, S. M., and Frye, C. A. (2006). In the ventral tegmental area, cyclic AMP mediates the actions of progesterone at dopamine type 1 receptors for lordosis of rats and hamsters. J. Neuroendocrinol. 18, 902-914. doi: 10.1111/j.13652826.2006.01488.x

Robertson, C. L., Puskar, A., Hoffman, G. E., Murphy, A. Z., Saraswati M., and Fiskum, G. (2006). Physiologic progesterone reduces mitochondrial dysfunction and hippocampal cell loss after traumatic brain injury in female rats. Exp. Neurol. 197, 235-243. doi: 10.1016/j.expneurol.2005.09.014

Saitoh, M., Ohmichi, M., Takahashi, K., Kawagoe, J., Ohta, T., Doshida, M., et al. (2005). Medroxyprogesterone acetate induces cell proliferation through up-regulation of cyclin D1 expression via phosphatidylinositol 3-kinase/Akt/nuclear factor-kappaB cascade in human breast cancer cells. Endocrinology 146, 4917-4925. doi: 10.1210/en.2004-1535

Sakamoto, H., Ukena, K., Takemori, H., Okamoto, M., Kawata, M. and Tsutsui, K. (2004). Expression and localization of 25-Dx, a membrane-associated putative progesterone-binding protein, in the developing Purkinje cell. Neuroscience 126, 325-334. doi: 10.1016/j.neuroscience.2004.04.003

Sayeed, I., Parvez, S., Wali, B., Siemen, D., and Stein, D. G. (2009). Direct inhibition of the mitochondrial permeability transition pore: a possible mechanism for better neuroprotective effects of allopregnanolone over progesterone. Brain Res. 1263, 165-173. doi: 10.1016/j.brainres.2009.01.045

Selmin, O., Lucier, G. W., Clark, G. C., Tritscher, A. M., Vanden Heuvel, J. P., Gastel, J. A., et al. (1996). Isolation and characterization of a novel gene induced by 2,3,7,8-tetrachlorodibenzo-pdioxin in rat liver. Carcinogenesis 17, 2609-2615. doi: 10.1093/carcin/ 17.12.2609

Selye, H. (1942). Correlations between the chemical structure and the 
pharmacological actions of the steroids. Endocrinology 30, 437-453. doi: 10.1210/endo-30-3-437

Seth, P., Fei, Y. J., Li, H. W., Huang, W., Leibach, F. H., and Ganapathy, V. (1998). Cloning and functional characterization of a sigma receptor from rat brain. J. Neurochem. 70, 922-931. doi: 10.1046/j.14714159.1998.70030922.x

Singh, M. (2001). Ovarian hormones elicit phosphorylation of Akt and extracellular-signal regulated kinase in explants of the cerebral cortex. Endocrine 14, 407-415. doi: 10.1385/ENDO:14:3:407

Sleiter, N., Pang, Y., Park, C., Horton, T. H., Dong, J., Thomas, P., et al. (2009). Progesterone receptor A (PRA) and PRB-independent effects of progesterone on gonadotropinreleasing hormone release. Endocrinology 150, 3833-3844. doi: 10.1210/en.2008-0774

Smith, J. L., Kupchak, B. R., Garitaonandia, I., Hoang, L. K., Maina, A. S., Regalla, L. M., et al. (2008). Heterologous expression of human mPRalpha, mPRbeta and mPRgamma in yeast confirms their ability to function as membrane progesterone receptors. Steroids 73, 1160-1173. doi: 10.1016/j.steroids.2008.05.003

Strauss, J., and Barbieri, R. (2004). Yen and Jaffe's Reproductive Endocrinology. 5th Edition. Philadelphia, PA: Saunders.

Su, C., Cunningham, R. L., Rybalchenko, N., and Singh, M. (2012). Progesterone increases the release of brain-derived neurotrophic factor from glia via progesterone receptor membrane component 1 (Pgrmc1)-dependent ERK5 signaling. Endocrinology 153, 4389-4400. doi: 10.1210/en.2011-2177
Swiatek-De Lange, M., Stampfl, A., Hauck, S. M., Zischka, H., Gloeckner, C. J., Deeg, C. A., et al. (2007). Membrane-initiated effects of progesterone on calcium dependent signaling and activation of VEGF gene expression in retinal glial cells. Glia 55, 1061-1073. doi: 10.1002/glia.20523

Thomas, P. (2008). Characteristics of membrane progestin receptor alpha (mPRalpha) and progesterone membrane receptor component 1 (PGMRC1) and their roles in mediating rapid progestin actions. Front. Neuroendocrinol. 29, 292-312. doi: 10.1016/j.yfrne.2008.01.001

Thomas, P., Pang, Y., Dong, J., Groenen, P., Kelder, J., De Vlieg, J., et al. (2007). Steroid and G protein binding characteristics of the seatrout and human progestin membrane receptor alpha subtypes and their evolutionary origins. Endocrinology 148, 705-718. doi: 10.1210/en.20060974

Tokmakov, A. A., and Fukami, Y. (2009). [Nongenomic mechanisms of progesterone]. Tsitologiia 51, 403-416.

Towle, A. C., and Sze, P. Y. (1983). Steroid binding to synaptic plasma membrane: differential binding of glucocorticoids and gonadal steroids. J. Steroid Biochem. 18, 135-143. doi: 10.1016/0022-4731(83)90079-1

Vasan, R., Vali, M., Bell-Horner, C., Kaur, P., Dillon, G. H., and Singh, M. (2003). "Regulation of the GABA-A receptor by the MAPK pathway and progesterone", in 33rd Annual Society for Neuroscience Meeting, (New Orleans, LA), 472.412 .

Vegeto, E., Shahbaz, M. M., Wen, D. X., Goldman, M. E., O’Malley, B. W., and McDonnell, D. P. (1993).
Human progesterone receptor A form is a cell- and promoterspecific repressor of human progesterone receptor B function. Mol. Endocrinol. 7, 1244-1255. doi: 10.1210/me.7.10.1244

Vitarbo, E. A., Chatzipanteli, K., Kinoshita, K., Truettner, J. S., Alonso, O. F., and Dietrich, W. D. (2004). Tumor necrosis factor alpha expression and protein levels after fluid percussion injury in rats: the effect of injury severity and brain temperature. Neurosurgery 55, 416-424. discussion: 424-415. doi: $10.1227 / 01 . N E U .0000130036$. $52521.2 \mathrm{C}$

Wang, J. M., Liu, L., Irwin, R. W. Chen, S., and Brinton, R. D. (2008). Regenerative potential of allopregnanolone. Brain Res. Rev. 57, 398-409. doi: 10.1016/j.brainresrev.2007.08.010

Wasserman, W. J., Pinto, L. H., O'Connor, C. M., and Smith, L. D. (1980). Progesterone induces a rapid increase in $[\mathrm{Ca} 2+]$ in of Xenopus laevis oocytes. Proc. Natl. Acad. Sci. U.S.A. 77, 1534-1536. doi: 10.1073/pnas.77.3.1534

$\mathrm{Xu}$, J., Zeng, C., Chu, W., Pan, F., Rothfuss, J. M., Zhang, F., et al. (2011). Identification of the PGRMC1 protein complex as the putative sigma-2 receptor binding site. Nat. Commun. 2, 380. doi: 10.1038/ncomms1386

Zheng, S., Huang, J., Zhou, K., Xiang, Q., Zhang, Y., Tan, Z., et al. (2012). Progesterone enhances vascular endothelial cell migration via activation of focal adhesion kinase. J. Cell. Mol. Med. 16, 296-305. doi: 10.1111/j.1582-4934.2011.01305.x

Zhu, Y., Bond, J., and Thomas, P. (2003a). Identification, classification, and partial characterization of genes in humans and other vertebrates homologous to a fish membrane progestin receptor. Proc. Natl. Acad. Sci. U.S.A. 100, 2237-2242. doi: 10.1073/pnas.0436 133100

Zhu, Y., Rice, C. D., Pang, Y., Pace, M. and Thomas, P. (2003b). Cloning, expression, and characterization of a membrane progestin receptor and evidence it is an intermediary in meiotic maturation of fish oocytes. Proc. Natl. Acad. Sci. U.S.A. 100, 2231-2236. doi: $10.1073 /$ pnas. 0336132100

Conflict of Interest Statement: The authors declare that the research was conducted in the absence of any commercial or financial relationships that could be construed as a potential conflict of interest.

Received: 20 June 2013; paper pending published: 01 July 2013; accepted: 19 August 2013; published online: 19 September 2013.

Citation: Singh $\mathrm{M}, \mathrm{Su} \mathrm{C}$ and $\mathrm{Ng} \mathrm{S}$ (2013) Non-genomic mechanisms of progesterone action in the brain. Front. Neurosci. 7:159. doi: 10.3389/fnins. 2013.00159

This article was submitted to Neuroendocrine Science, a section of the journal Frontiers in Neuroscience. Copyright (C) 2013 Singh, Su and Ng. This is an open-access article distributed under the terms of the Creative Commons Attribution License (CC BY). The use, distribution or reproduction in other forums is permitted, provided the original author(s) or licensor are credited and that the original publication in this journal is cited, in accordance with accepted academic practice. No use, distribution or reproduction is permitted which does not comply with these terms. 